\title{
De las múltiples voces
}

La diversidad de voces que se abren camino en este número, nos ofrecen un panorama que refleja las confluencias con las que tiene que vérselas la pedagogía. Se aprecian desde voces que narran el transcurrir cotidiano de la acción pedagógica, hasta las voces que analizan amplios panoramas de la pedagogía. Voces de niños y de maestros desde la escuela, mezcladas con voces de investigadores desde la universidad; de lo que ocurre en la escuela y, también, de lo que debería ocurrir.

La oscilación va de narraciones a conceptos. Nos informan segmentos de lo que ocurre en la escuela, con lo cual podemos, por ejemplo, transportarnos a una clase con estudiantes de primaria que explora la historia de su comunidad. Otros textos se centran en el análisis de la formación de maestros. Las narraciones nos transmiten principalmente imágenes y sensaciones. Nos participan de los mundos vividos en el oficio de maestro, tal como él mismo los aprecia e interpreta. Los conceptos nos proponen elucidaciones y nos invitan a participar de las discusiones propias del mundo académico.

El mundo vivido de la escuela discurre en un contexto concreto desde el cual se apuntalan demandas y resistencias, y se vigoriza o se atempera la acción pedagógica, condiciones que hacen de esta un asunto especialmente singular. Por su parte, los conceptos exigen aislar variables, en procura de asegurar precisión y consistencia; en aras de la solidez se abstraen de la singularidad, para ganar generalidad.

Lo pedagógico, entonces, se mueve entre generalidades y singularidades, entre la pretensión de exactitud y las circunstancias turbulentas que proporciona el contexto, entre lo preciso y lo impreciso. Las narraciones o relatos son acercamientos al contexto y en buena medida lo reflejan. Hemos aprendido, por vía académica, que los conceptos nos ayudan a descifrar qué puede haber detrás de la turbulencia, es decir, cómo estos contribuyen a escrutar lo que esconde la apariencia de los fenómenos tal como se nos presentan. En otras palabras, la pedagogía no escapa a la discusión clásica en torno a las relaciones entre existencia y esencia.

La turbulencia del contexto, es decir, lo que deviene en el espacio institucional de la escuela, lo que acontece en su cotidianidad, no es fácil de decir, de explicar, de comunicar, por la cantidad de variables que lo componen. La realidad escolar es compleja, porque es esquivo su desciframiento; no se deja prescribir, no se deja contener fácilmente para hacerla pervivir en los conceptos que son más estables y duraderos. La escuela es el ámbito de la contingencia, de constantes emergencias y desafíos, de satisfacciones finitas, de frustraciones inesperadas, pero también de logros que no son visibles a simple vista. Se cuentan y aceptan grandes dosis de impredecibilidad, aunque estas se den generalmente en un marco institucional predecible. En tanto la experiencia del maestro captura aquello que considera pertinente para su oficio, puede entenderse que este es depositario de una selección importante de la complejidad escolar, lo cual le permite sortear la turbulencia a la que se enfrenta cotidianamente. 
La experiencia del maestro está en el plano de la singularidad, pero cuando decide socializarla, es decir, cuando levanta la mirada en busca de otros interlocutores, emprende el tránsito de la singularidad a la pretensión de generalidad. La sistematización de experiencias es el lugar que mira y conjuga dos ámbitos: cotidianidad y conceptos; en otras palabras, acción pedagógica entrelazada a su significación. Al seleccionar lo pertinente del mundo vivido de la escuela para comunicarlo, implica también definir la manera de hacerlo. En este punto hay que preguntarse: ¿con cuánta libertad lo quiere comunicar el maestro? Cuando la experiencia se inscribe en un proceso de sistematización, incursiona en las reglas propias del rigor académico y su apropiación le permite el movimiento que conduce del relatar al conceptualizar. Si la experiencia se mantiene en el relato, el rigor de las reglas para comunicarla le ceden espacio a la imaginación. Mientras el relato se inscribe en el mundo de la literatura, la sistematización tiene que ver con la inserción en un campo teórico.

El espacio entre los relatos -o narraciones- y los conceptos es un terreno donde tendría cabida la construcción de una gramática, cuyas reglas permitan la expresión de tensiones y contradicciones en las que discurre la realidad pedagógica; mientras tanto, aquello que no cabe en el molde estrictamente conceptual lo ubicamos en el campo narrativo. Sabemos que en una acción pedagógica, en donde el contexto es parte de la acción, se producen nuevas realidades que demandan nuevas designaciones y significaciones. Para que estas puedan expresarse con amplitud, reflejando mas cabalmente una experiencia, se requiere flexibilidad y creatividad, y esto significa apelar a la mayor riqueza posible del lenguaje para alcanzar la prodigalidad de una acción pedagógica. Es a través de éstas experiencias de maestros que nos llegan las voces de los niños y niñas de primaria que preguntan a su maestro cómo es la historia de su comunidad, mientras recorren los caminos de su vereda; voces que se unen a las de los académicos en un concierto de voces constituyentes del mundo de la pedagogía.

Raúl Barrantes 